City University of New York (CUNY)

CUNY Academic Works

Publications and Research

Hunter College

1997

\title{
Are Salaries in the National Hockey League Related to \\ Nationality?
}

William (Bill) H. Williams

CUNY Hunter College

David A. Williams

SJ Sharks \% Anaheim Ducks

\section{How does access to this work benefit you? Let us know!}

More information about this work at: https://academicworks.cuny.edu/hc_pubs/48

Discover additional works at: https://academicworks.cuny.edu

This work is made publicly available by the City University of New York (CUNY).

Contact: AcademicWorks@cuny.edu 


\section{Hockey executives respond better to "Show me the money" when the player has a Scandinavian accent.}

\section{Are Salaries in the National Hockey League Related to Nationality?}

\section{Bill Williams and David Williams}

\section{Public Salaries}

National Hockey League (NHL) player salaries were made public for the first time relatively recently. The new policy gave everybody, including the players, endless room for speculation. Some discussion focused, not on the salaries of the stars so much, as on the more average NHL players, particularly the number of seemingly average Swedish and Finnish players drawing above-average salaries. Opinions about the playcrs from Russia and the former Czechoslovakia were not so clear, perhaps a result of the presence of some great Russian stars, whose play clearly merited serious money. Interestingly, at about the same time, there was discussion about the many players from Russia and the former Czechoslovakia in the minor leagues and the seemingly few players from Sweden and Finland. Mostly, the large numbers from Russia and Czechoslovakia were attributed to the social upheavals in those countries and until now, no one seemed to understand just how these numbers are inversely related to salaries.
In this article, we examine how opportunities for players from different countries vary and how salaries in the NHL are affected by these variations. For example, Canadian and U.S. players have essentially no alternative hockey career options, but Swedish players have excellent home leagues if they choose them. Does this affect their relative NHL salaries? Scandinavian salaries are clearly high, and it scems like a possible cause.

\section{Entry Salaries Are Critical}

A player's first salary in the National Hockey League dominates his career. A high initial salary tends to be maintained, and raising a lower one significantly is not easy to do. Restrictions on player "free agency" are important. After a player signs an NHL contract and until age 32, "free agency" is never quite unrestricted. That salaries are then constrained over time should not be surprising; economic theory tells us to expect it. One implication is that the alternative career opportunities avail- able to a player at the time of first salary negotiations are very important because these alternatives supply the player with leverage at a useful time.

\section{Differing National Opportunities}

A surprising number of countries supply players to the NHL, but sixSweden, Finland, Canada, the United States, Russia, and the former Czechoslovakia-supply well over $90 \%$. Career options differ greatly in these countries.

Prior to 1989, players from Russia and Czechoslovakia had few career options. They always played in their homeland; to play in North America required serious personal risk. But after the political upheavals in those countries, opportunities in North America opened up while, simultaneously, the viability of the options at home deteriorated. Some of these players wanted to use their hockey careers simply to get to North America, even if a highly paid, "star" career seemed out of reach. As an 
Table 1-Median NHL Salaries and Ranks by Country and Position, $1993 / 94$ (thousands of U.S. dollars)

\begin{tabular}{|c|c|c|c|c|c|c|c|c|}
\hline & CAN & CSSR & FNN & SWEE & & USA & USSRR & Overall \\
\hline DEF & 425.4 & 325.5 & 650.1 & 625 & 2 & 475,3 & 3006 & 410 \\
\hline 2 & 375.4 & 350.5 & $550 \quad 2$ & 600 & 1 & 325.6 & $400, \mathbf{3}$ & 375 \\
\hline & 388,3 & 337.5 . 6 & $600 \quad 2$ & 625 & 1 & 386.5 .4 & 357.5 .5 & 394 \\
\hline
\end{tabular}

to have been the result of options that were open to him. but rather it was because his contract was pulled into line behind that of Lindros. On the other hand. Alexei Yashin's much lower contract appears to have resulted from his perceived lack of options. As soon as he got to Ottawa, he realized how out of line his contract was and began loudly complaining.

What is the potential impact of these various career options on salaries?

\section{The Likely Effects of Differing Opportunities}

The Swedes and Finns have the best options, so ther should be the best paid.

Moreover, because the options of the extra incentive, Russian players are, for their first year, forgiven income taxes in both the United States and Canada. As a result of these factors, it is not surprising that there are many Russian players in the North American minor leagues.

Among the countries that supply significant numbers of players to the NHL, the Swedish and Finnish players have the best hockey career options. The Swedish leagues, particularly, are a good choice for many players; most players are reasonably well off. Additionally, Swedish and Finnish players do not receive the first-year tax break in North America that the Russian players do. Nevertheless, because the Swedish leagues do not have the very big money of the NHL, the best players are probably better off in the NHIL. As a result of this, in contrast to the Russians, there are few Swedish and Finnish players in the North American minor leagues.

Professional players from Canada and the United States are subject to the NHL entry draft and have essentially no other choices. During the brief life of the World Hockey Association, a league that competed with the NHL, players had a very real alternative career option and, for a while, player salaries increased rapidly.

Some U.S. and Canadian players, such as Kelly Kisio, play their way into the NHL by going to Europe, but there are severe European league restrictions placed on the number of import players. And even this modest alternative has declined in value to North American players because many Russians are competing for the limited number of positions available in
Europe. More recently, competitive developments in the Internationa Hockey League (IHL) have given some players temporary leverage, and some, ed by the New York Rangers, used this option. Overall, the impact of the IHL and the European leagues on NHL salaries has been small.

Olympic hockey has been used to bolster one's career and salary. Paul Kariva used his Olympic career very successfully: But with the Olympics

\begin{tabular}{|c|c|c|c|c|c|c|c|c|}
\hline \multicolumn{9}{|c|}{$\begin{array}{l}\text { Table 2-Mean NHL Salaries and Ranks by Country } \\
1993 / 94 \text { (thousands of U.S. dollars) }\end{array}$} \\
\hline & $C A N$ & CSSR & FINN & & SWED & USA & USSR & Overall \\
\hline DEF. & 5094 & $402 \quad 5$ & 559 & 3 & 5832 & 6111 & 3516 & 513 \\
\hline FOR. & $\begin{array}{lll}586 & 4\end{array}$ & $473 \quad 6$ & 626 & 2 & 6451 & $510^{4}$ & $522=5$ & 564 \\
\hline D\&F & 5613 & 4496 & 601 & 2 & 6121 & 5484 & $459 \quad 5$ & 547 \\
\hline
\end{tabular}

held only every four years, this requires chance timing and, in any event, is available only to the top minor league stars. Again, use of this mechanism to increase salary is just not widespread.

It is certainly true that entry-lcvel salaries for carly-round picks jumped dramatically in recent years. Presumably, this has resulted from player leverage at the time of NHL entry. At that time, a top player has invariably received considerable publicity and does have the option of returning to his minor league team.

Eric Lindros put great pressure on the NHL, but it is hard to think of other players who could have exerted similar pressure. Alexandre Daigle's subsequent large contract does not appear
Czcchs and Russians have deteriorated at home, they are probably paid less than the Swedes and Finns and perhaps quite a bit less. The Russians. with their dominance of international competition and with well-known NHL superstars, have made impressive impacts on hockcy in North America. As a result, one might speculate that the Russians are paid more than the $C$ zechs.

What about the Canadians and Americans? Although Canadian players have no options, they certainly are

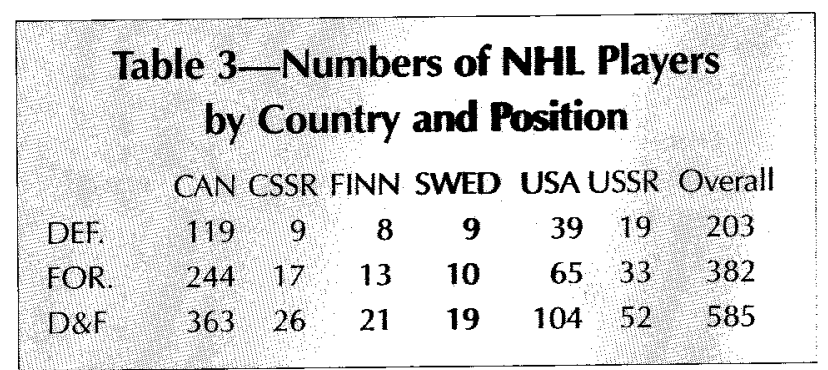


Table 4 -Standard Deviations of NHL.

Salaries by Country and Position, 1993/94 (thousands of U.S. dollars)

\begin{tabular}{|c|c|c|c|c|c|c|c|}
\hline & CAN & CSSR & FINN & SWED & USA & USSR & Overall \\
\hline DEF & 330 & 203 & 164 & 245 & 529 & 137 & 361 \\
\hline & 732 & 328 & 354 & 401 & 430 & 428 & 639 \\
\hline & 630 & 289 & 284 & 329 & 470 & 359 & 559 \\
\hline
\end{tabular}

skilled plavers, and Canadians are verinfluential in team management. The Canadians should be well paid. Americans. led by players like Brian Leetch and Jeremy Roenick, finally appear to have orercome the old belief that they cannot play hockey. So, although most Americans are forced into college hockey by severe NCAA penal- were the other way around.

But what are the facts?

\section{Base Salaries}

Only the six major countries are included in this analysis. The salary data relate to the fall of 1993. and the on-ice data are for the complete 1993/94 season. No goalies are included. Players who playcd fewer than 15 games are also excluded. Consequently, this analysis eliminates the injured, the rookies, and marginal players. The average age of this group is 24 , whereas it is 27 for the players in

\begin{tabular}{|c|c|c|c|c|c|c|c|}
\hline \multicolumn{8}{|c|}{ Table 5-Median NHL Performance Indexes 1993/94 } \\
\hline & CAN & CSSR & FINN & SWED & USA & USSR & Overall \\
\hline DEF. & 5094 & 4025 & 5593 & 5832 & 6111 & 3516 & 513 \\
\hline FOR. & 5864 & 4736 & 6262 & 6451 & 5104 & 5225 & 564 \\
\hline D\&F & 5613 & 4496 & 6012 & 6121 & 5484 & 4595 & 547 \\
\hline
\end{tabular}

ties against them if they even try out for a Canadian junior team. they may well be paid comparably to the Canadians.

Finally, how does the position that a player plays affect salary? Because forwards get most of the points and much of the publicity, it may be that forwards have higher salaries on the average than defensemen. Certainly, many of us would be surprised if it the database, but otherwise there seems to be little that is systematic about this group.

Salary data, in general, are typically very skewed. NHL salaries are no exception with the result that the standard analysis of means is completely dominated by the most highly paid players. Because we do not want to focus on these highly paid players, it is more informative and much simpler to present the results in terms of medians. The median base salaries for the included players are given by country and position in Table 1 .

First, we should not be surprised that the overall salaries of the Russians and Czechs are the lowest and next to lowest. Moreover, we should not be surprised that the Finns and Swedes have the highest salaries. Furthermore, we observe that, as expected, Canadian and American salaries are very close to each other.

There is a large difference between the Swedish and Finnish salaries and the salaries of the other four countries. With distributional assumptions, we tested the single degree of freedom comparing the Swedish/Finnish salaries to the other four countries. This linear combination is statistically significant at the .01 level.

Many defensemen are not spectacular and do not score many points. So, with our reasoning, how would a stayat-home Czech or Russian defenseman, who wants to come to North America regardless, do in salary negotiations? Apparently, not great. Table 1 shows that the median salaries of the Russian and Czech defensemen are the lowest, fifth and sixth, respectively. Russian forwards are somewhat better off. Swedish and/or Finnish players have the highest salaries in both positions. If there is a surprise in Table 1 , it might be that American forwards rank sixth among the forwards and that their median salary is very much lower than that of American defensemen.

\section{Principal Components to Reduce Dimensionality}

It is common that a large number of measurements (often highly correlated) are made for each unit in a study. For example, each player in the hockey salary study provides measurements on games played, goals scored, goals assisted on, and more. Suppose that $p$ variables are measured for each unit and denote their values on the ith unit as $x_{i}=\left(x_{i}, x_{i 2}, \ldots, x_{i p}\right)$. The method of principal components creates a new set of $p$ variables $z_{i}=\left(z_{z_{1}}, \ldots, z_{i}\right)$ where

- each $z_{i j}$ is a linear combination of the components of $x_{i}$

$$
\sum_{i} z_{i} z_{i j}=0
$$

- the new variables are uncorrelated;

- the first few principal components $\left(z_{i 1}, z_{2}, \ldots, z_{i q}\right)$ for $q<p$ contain much of the total observed variation of all of the $x_{i} s$.

Mathematically, the principal components are determined as the eigenvectors of the covariance (as correlation) matrix of the original variables. An examination of the eigenvectors allows one to determine which variables are important constituents of each prineipal component. In the hockey study, the first principal component contained major contributions from games played, goals scored, goals assisted on, shots taken, and power-play goals. All of these can be considered offensive statistics so that the first principal component is an overall measure of offensive performance. This is not unusual; the first few principal components often represent an average of similar variables. 
Although we have chosen not to allow this analysis to be dominated by the most highly paid players, it is interesting to compare mean salaries to the medians. Table 2 displays salary means.

Notice that, for the Finns and Swedes, the corresponding mean and median salaries are very close to each other and, indeed, two means are smaller than the medians. This implies that these salary distributions are skewed very little or even to the left, in the opposite direction from that usually found in salary distributions. There are fow Finnish and Swedish players in the lower salary ranks, which certainly fits with our speculation that only the best of these players leave their home countrics. In contrast, all of the other means are considerably larger than their corresponding medians.

Tables 3 and 4 are statistical companions to Tables 1 and 2 .

Although the salary observations made so far may be interesting, it is entirely possible that these comparisons are no more than a reflection of the players' on-ice ability. The Finns and Swedes who come to North America may simply be superior hockey players and are paid accordingly. But then, if this is really true, we ought to be able to relate thesc salary differences to some aspect of on-ice performance.

\section{Performance Measurement}

How should we evaluate on-ice performance? There are many statistics available, including games played, goals scored and assisted (each of these is also available separately for even-strength goals, power-play goals, and short-handed goals), penalty minutes, shots-ongoal, and plus/minus. (Plus/minus is the difference between the number of goals a player's team scores while he is on the ice minus the number the opposing team scores.) Selecting one or two of these variables will not be suitable for all players and, in any event, can always be second-guessed. In an earlier work by the authors, the statistical method known as principal components was used to reduce the dimensionality of the data to two indexcs, OPI, which measures offensive performance, and EPI which measures defensive efficiency.
This technique is described briefly in the accompanying box. Although we do not present the details here, EPI appears to have little to do with salary, even for defensemen.

Table 5 shows the median OPI index of the players by position and country.

An interesting observation with respect to the data summarized in Table 5 is that the variation in performance within countries is greater than the variability among countries. This is especially true for the forwards. This unusual statistical characteristic may not be a surprise in hockey terms, however. Indeed, it might have been expected because it points out that the team general managers and player scouts are consistent about their sclections. During the player selection drafts, teams reach into the player pool of each country only as far as they believe the players will be useful in the NHL; then ther stop. And they do this consistently within each country with the result that the players coming from each country tend, on average, to be similar in ability. The best players recruited each year may vary from country to country, but that evens out over several years.
Certainly, an overall revicw of current NHL players does not permit one to say that the best players in the NHL are from any one particular country. This is an important observation because it means that country differences in player ability are not likely to be a credible explanation of country differences in salaries.

\section{Offensive Performance and Salary}

A linear regression analysis using the logarithm of salary as the response variable and country, player position, and both offensive and defensive performance measures as predictors indicates that only country and offensive performance have significant roles in explaining salaries. All players in the database were included.

This statistical confirmation will not surprise hockey fans, who know that general managers in the NHL believe that scoring is a natural talent and, unlike defense, cannot be taught; that is, teams will pay for scoring ability but not necessarily for defense.

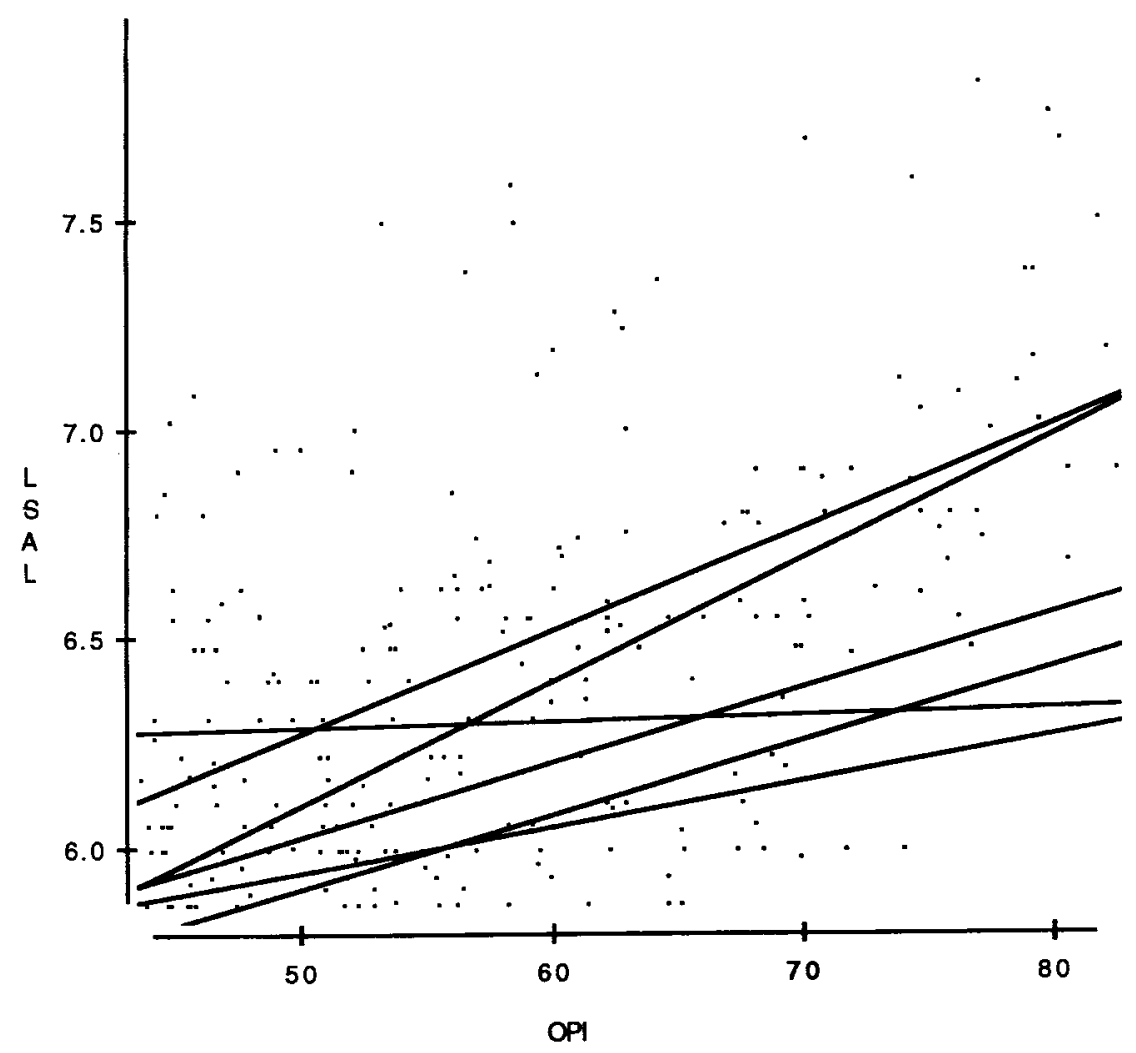

Figure 1. In(salary) versus the performance index, OPI. 


\begin{tabular}{|c|c|c|c|c|c|c|c|c|c|c|}
\hline \multirow{2}{*}{ DEF. } & CAN & \multicolumn{2}{|c|}{ CSSR } & \multirow{2}{*}{$\begin{array}{c}\text { FINN } \\
14.31 \quad 1\end{array}$} & \multicolumn{2}{|c|}{ SWED } & \multicolumn{2}{|c|}{ USA } & \multicolumn{2}{|c|}{ USSR Overal } \\
\hline & 3 & 9.19 & 4 & & 10.64 & 2 & 9.07 & 5 & 6.136 & 9.43 \\
\hline 8.24 & 4 & 8.39 & 3 & 11.861 & 9.23 & 2 & 6.72 & 6 & 7.645 & 8.14 \\
\hline 8.74 & 3 & 8.47 & 4 & 12.851 & 10.46 & 2 & 7.98 & 5 & 7.316 & 8.59 \\
\hline
\end{tabular}

Some insight about the relationship of salary and OPI can be found in Fig. I which displars the regression lines of In(salary) on OPI separately for each of the six countries. The lines for five of the six countries slope up positively, as expected. The highly paid Finnish players are represented by the top linc (at the right and generally across the plot). The Swedish plavers, however, are represented br the horizontal linc. It happens that in the regression analysis players were differentiated by positions, forwards and defensemen. The regression for Swedish defensemen rises clearly up to the right in the expected direction, but the regression for Siredish forwards has a decidedly negative slope. The plotted line is the melded result. It should be recalled that a small number of Swedish players, 19. appear in the database.

The analysis to this point raises a far more complex question, than the question we consider in this article-namely, what are the various factors which influence how NHL players are paid? For example, salary depends on much more than just position or performance measure. Players who get many penalties do not have to score points in order to earn high salaries. Moreover, the top $10 \%$ of the players appear to be paid with a completely different formula from the rest. We have a more detailed study underway and plan to report on the findings in a later article.

\section{Performance-Adjusted Salaries}

Because OPI is a significant predictor of salarics, we used performance to adjust salaries. For each player, wc divided salary by OPI to obtain a measure of salary weighted by offensive performance. Table 6 shows the median of these numbers by country and position.
Confirming our expectations, on a "dollar per index point," the Swedes and the Finns are the most highly paid. On this same basis, the Russians are the lowest paid, and the Americans have slipped behind the Czechs. Intcrestingly, except for the Russians, defensemen are paid better for offensive performance than forwards. This may be a consequence of the nature of the adjustment because defenseman have much lower OPI's but only slightly Iower salaries. Unfortunately for them, the Russian defensemen receive the fewest dollars per index point among the 12 classifications in Table 6.

\section{Discussion}

NHL base salaries differ significantly from country to country. Furthermore, these country differences cannot be satisfactorily explained by differences in player ability because the players from the six countries tend to be quite similar.

On a performance-adjusted basis, Swedish and Finnish players are paid the highest, and by a significant amount. Russians are paid the least, slightly less than American players, who are fifth. In the light of their on-ice performance, it is somewhat surprising that the Americans wind up fifth. The Czechs are fourth, and the Canadians are third, as they were in the rankings of raw salaries. By position, Finnish defensemen are paid the most and Russian defensemen the least. Among the forwards, American forwards are the lowest paid.

The differing economic bargaining power available to the players is a very appealing explanation of these country salary differences. Salary comparisons are always complex, but the results here fit extremely well with the theory that salary is determined by the quality of alternative career options available to players at their time of entry into the
NHL. The Swedes and Finns have the best options, and it is reflected in their salaries. The players from the other four countries do not have the same career options and are paid significantly less, even on a performance-adjusted basis. That the Russians have the lowest salaries is not surprising. Russian society has severe problems, and playing in North America offers the possibility of both a new socicty and an above-average salary in that society. Both of these factors may attract Russian players. Similar remarks about the lack of options seem to apply to the Czechs, although they do wind up more highly paid than the Americans. Perhaps, the Americans have more to learn than just "playing the game."

\section{Extensions}

The implications of the results for the salaries of all players are considerable. Especially important is the observation that player salaries arc critically dependent on starting salaries. The 1995 Collective Bargaining Agreement between the NHL and the Players' Association contains a "cap" on entry salaries that has the potential to lower all salaries, or at least restrain them. This is possible because rc-negotiated salaries are often achieved by studying "comparable" players, without regard to country. So, if the higher salaries afforded to some players by their particular national economic opportunities are curtailed, it may tend to push down all salaries at the time of re-negotiation.

\section{References and Further Reading}

Cruise, D., and Griffiths, A. (1992), Net Worth, Toronto: Penguin Books.

NHL Yearbook (1994), Toronto, NHL.

Lackritz, J. R. (1990), "Salary Evaluation for Professional Baseball Players," The American Statistician, 44, 4-8.

Williams, B. (1994), "Performance Indices for On-Ice Hockey Statistics," in Proceedings of the Section on Statistics in Sports, American Statistical Association, 50-54. 